Bibby, T. (2009). How do children understand themselves as learners? Towards a learner-centred understanding of pedagogy. Pedagogy, Culture and Society, 17(1): 4155.

\title{
How do children understand themselves as learners? Towards a learner-centred understanding of pedagogy
}

\section{Tamara Bibby, Institute of Education, University of London}

This paper challenges notions that pedagogy is predominantly rational, conscious and deliberate. Drawing on two research projects about experiences of learning in primary and secondary schools, the paper explores pedagogic relationships and the ways these structure and enable different kinds of learning and knowledge creation. The data are read with (Felman, 1987) the psychoanalytic writings of Wilfred Bion to investigate the ways in which knowing and learning are bound up in the unconscious emotional flows of classroom relationships. A learner - centred understanding of pedagogy is tentatively and critically developed. The desirability and some simultaneous difficulties of working with such notions of pedagogy are discussed.

Key words: Pupil voice; psychosocial understandings; Bion; K links; identity

\section{Introduction}

The tranche of reports released in February from a review of primary education ${ }^{\mathrm{i}}$ were reported in the press as showing that children in England are unhappy. They highlighted the pressure on teachers to ensure that pupils attained national and local targets and suggested that these accountability pressures are impacting the curriculum and pupil experiences of schooling (Curtis 2008). These reports follow recent claims that childhood in the UK is becoming increasingly 'toxic' (Palmer 2006) and confirm earlier work by Webb \& Vulliamy which found that ... 
High stakes testing, which holds schools and teachers accountable for pupil attainment in literacy and numeracy, has narrowed the curriculum, diminished opportunities for teachers to develop the whole child, caused considerable stress for many children and changed the basis of teacher-pupil relationships $(2006,153)$

Elsewhere there is growing awareness of the undesirable impacts of objectives-driven teaching (see for example Torrance 2007; Sadler 2007). The technical-rationalist dream of a knowable, measurable, controllable approach to teaching and learning seems to be unravelling although there is not yet any official recognition of this. In this paper I draw on data that resonates with these findings to explore 'pedagogy' and begin to suggest an inchoahte definition that takes account less of what we, as adults and educators, might think it should mean, and more of the experiences of pupils. I will provide some discussion of why such an endeavour might be important, but also why it is likely to prove challenging to enact.

Rational definitions of pedagogy suggest that it is, for example, 'any conscious activity by one person designed to enhance the learning in another' (Watkins \& Mortimore 1999,16). If pedagogy is something about what happens to make or facilitate learning, the traditional focus has been on the actions of the pedagogue, the teacher. Such a concern, as Britzman has noted, emanates from education's desire 'to be deliberate - conscious really - and ... its design and institutional form proceed from the assumption of building incremental knowledge upon the edifice of the learner' (Quoted in Pitt, Robertson \& Todd 1998, 2). I will suggest that, if we take seriously current calls to reinsert or listen to the experiences of pupils, any simple story of a teacher/learner, 'doer' /'done to' (Benjamin 2004) becomes problematic; the young people themselves become part of something more relational, less linear and less completely rational. Learning may be found to be, not only non-linear but perhaps fractal in its complexity. However inconvenient it may be, there is more to human interaction than the rational and the deliberate; as Winnicott has pointed out: 'The unconscious may be a nuisance for those who like everything tidy and simple, but it cannot be left out of account by planners and thinkers. ... In human affairs, thinking is but a snare and a delusion unless the unconscious is taken into account.' (cited in Britzman 2003, 97). I use Winnicott here to problematise the conscious/ rational basis of much current theorising of pedagogy and to assert the importance of 
unconscious processes. But I do this in a mindful way: to acknowledge that there may be more going on than first meets the (conscious, adult) eye. Yet, the seductive allure of those apparently simple problems and tidy answers remains. As Britzman reminded us, turning away from a simple, tidy world brings us into contact with the messy and the painful: 'confronting the unconscious means de-idealizing the self, accepting one's constitutive vulnerability, and noticing the fragility of consciousness.' (p109) This article will begin to explore why taking such a difficult turn might be worth the effort.

\section{The research projects}

To develop this tentative redefinition of pedagogy I draw on data from two projects. One data set is drawn from group interviews done with pupils aged 11-13 years, exploring their experiences of learning in and between different departments of the secondary school curriculum. The focus of this research also included the work of one of their teachers (Stephen) who had more than 10 years of experience in that school. The unexpected nature of the interactions from these initial group interviews provides one half of the story.

The other half of the story emerges from a 3-year project that examined children's learner-identities in primary school mathematics. ${ }^{\text {ii }}$ The data reported here came from the 10 year-old pupils and their teacher (Rachel), who was newly qualified. The contrast that these two teachers provided was stark and this comes across clearly in the ways their pupils talked about them and the learning opportunities they provided. There were important differences between them as professionals and their working contexts. Not least of these differences was Steven's specialist teaching role which contrasts strongly with Rachel's generalist status. In a time of national specialist mathematics teacher shortages (Smith 2004), Steven was a senior member of a well established team with collegial working habits and a supportive head teacher. While Rachel was also working in an established and stable staff, there was less focus on teaching than there was in the Secondary school context. Instead, much use was made of pre-planned lessons available on the internet and more attention was given to the management of external policy requirements. The acceptance of 'new managerialist' (Ball 2003) practices, therefore, was much more evident in the primary school. 
The use I wish to make of the data is to draw attention to the apparently different learning agendas among pupils and teachers. My suggestion is that pedagogy can be usefully reconsidered if we draw on pupils' concerns and read these with (Felman 1987) theoretical frames that enable us to begin to think about some of the unconscious processes associated with learning in the classroom. To do this I will draw on aspects of the work of group psychoanalytic theorist Wilfred Bion (1961), his notion of the 'links' and particularly the $\mathrm{K}$ (knowledge) link. I do this to ...

explore the implications for education of the inseparability of knowledge and subjective experience, the unconscious conditions of all belief systems, and the presence of fantasies which are always in on the act of making knowledge. (Pitt, Robertson \& Todd 1998, 4)

\section{A warning/caveat}

The language of psychoanalysis can appear inappropriate and sit uncomfortably with readers unfamiliar with its terms and usages. The metaphors may seem uncanny or inappropriately aggressive leading to defensive readings of psychoanalytically informed analyses of research. This paper will suggest that there are teachers whose actions 'block' or lead to 'an attack' upon their relationships with their pupils. I want to be clear that all actions so ascribed are unconscious actions. That is, they are not deliberate. I am not suggesting that any teacher would deliberately sabotage their relationships with their pupils, indeed my experience of reporting this research to teachers is that they are often distressed that their well intentioned actions might have such effects.

I suggest that our culture is not one that prioritises a focus on relationships and relationality and that schools reflect this general trend. Further, because of the pressures from outside, and the power imbalance that comes with age differentials, this may even be magnified in schools. However, I suggest that for as long as relationships remain unexamined or reduced to technical prescriptions (objectives, targets, scripted three-part lessons etc.) we will continue to have no way of observing or thinking about pedagogic relationships. And while we seek to protect the status of an idealised 'teacher' and to maintain their status as 'superior' to (hierarchically above 
and knowing more/better than) their learners, we will continue to compound the situation institutionally.

I report on individual teachers here but the points I want to draw are general and relate to the ways of relating; ways we can all fall into whatever our level of experience or the age of our pupils.

\section{Wilfred Bion and processes involved in learning}

Bion is centrally concerned with the development of thoughts and knowledge and the use to which thoughts may be put. Key to the argument here is his belief that an important aspect of the human condition is that people can 'choose' to tolerate frustration and difficulty. For Bion this ability to tolerate (psychic) pain and frustration is central to learning since all learning requires we take a risk. To move from not knowing to knowing we must necessarily transit through a period which will involve uncertainty, frustration and anxiety and this uncertainty inevitably carries risk. Failure and success both entail risk. It is relatively easy to see that failure potentially carries shame (Bibby 2002). Less obvious, however, is the difficulty that success can bring (Lucey, Melody \& Walkerdine 2003). It is important to remember that any 'decision' here is not a conscious one but is part of the unconscious processes played out in our relationships. That does not mean that we cannot become aware of some of our 'decisions' at this level and work with them, but it does mean that to do so is not straightforward.

Bion suggests that all lasting effects come from feelings that belong to the love-hate spectrum of emotional activities: Love, Hate, Knowledge, talked about as the L, H and $\mathrm{K}$ links and the negatives of these denoted as $-\mathrm{L},-\mathrm{H},-\mathrm{K}$ ("minus L" etc). These 'minus' links are not an absence of the emotional activity, nor are they its opposite. Rather they represent a block to it, a refusal to engage, a repression. If a minus link is experienced as dominating a relationship then 'the process of understanding within the relationship is stopped and reversed; meaningful experience may be destroyed' (Symington \& Symington 1996, 29). Bion's interest is in 'the application of thought to emotional experience', and his work is founded in a belief that 'an emotional experience cannot be conceived of in isolation from a relationship' (Bion 1962, 42). 
In this way thought becomes connected to relationship. Discussing Bion's insistence on the centrality of the relationship, Deborah Britzman explains:

having to learn is [not] an experience that can be known in advance. And this radical uncertainty ... is the structuring tension in education. On the one side there are passionate scenarios of love, hate and aggression; on the other side, indebtedness, promise, and forgiveness. The work of thinking carries traces of the disturbances of both sides, but what invokes the need to think, as opposed to the capacity to think, is the presence of the other. $(2003,28)$

Relationship here is the inevitable result of human interaction, those we know and interact with are in relationship with us, and while a relationship may be facilitative or blocking (and indeed may be both of these things in different contexts and at different times) it is neither a 'good' nor a 'bad' thing; it just is. Bion's work offers a powerful way of thinking about knowledge, knowing and relatedness and as such it has potential implications for teachers and teaching and may enable us to begin to theorise pedagogy somewhat differently. However, I come to this later and will start by offering a consideration of the contrasting data sets.

\section{Data from pupils in Years $7 \& 8$}

In this analysis of the secondary school interviews I explore the pupils' responses highlighting where these stand in relation to adult agendas. These interviews were conducted by a female teacher who was not a member of the maths department but who was collaborating in the cross curricular investigation within the school.

\section{Not being heard and the different agendas}

Asked whether 'the way you learn in maths lessons [is] different to the way you learn in other subjects?', the Y8 pupils talked first about English lessons. The extract below is from the end of their answer to this question when they had reached consensus and were reflecting on their conversation. There are several points of note in this extract. On one level, the data is familiar to researchers in maths education - pupils' experiences of maths being different to other lessons. We can also see that the pupils located the difference in the maths teacher (Oliver) and it is clear they weren't too pleased with his pedagogy. However, the last piece of the exchange is also 
interesting. ${ }^{\text {iii }}$ In other subjects the way they teach there isn't really that much difference it's actually quite similar but in maths it's really different.

Interviewer so what is different about maths?

The way they make you do it. With Oliver if you do it wrong you have to do it again.

Yeah, I had to do my work twice because I did one thing wrong He gives you a detention.

He tells you off in class

Int. So that's a different way of teaching, so maths use that way of teaching?

Sometimes

To get out of the class as soon as possible you have to do most of your work. If he's not proud of your work he'll keep you in for like five minutes afterwards going over it to get you aggravated.

But what he does, yeah, is he leaves it 'til five seconds before the pips go and then tells us our homework and then it takes like five minutes to write it down. Basically we're getting a detention.

Int Is that different to other subjects?

I think it's different teachers.

Int No, we're talking about subjects. ...

Throughout these interviews with groups of pupils the teacher/interviewer was repeatedly thwarted in her efforts to get the pupils to focus on mathematics. The last three lines of the transcript highlight the way she repeatedly moved away from the intersubjectivity that animated the pupils. She kept trying to move back to an abstracted notion of mathematics that could exist outside the relationships or that was capable of standing alone. This unwillingness or inability to stay with the intersubjectivities that the pupils kept returning to may have been to do with some professional discomfort around talking to pupils about colleagues, it may have been a result of her inexperience as an interviewer, or it may have been that the interviewer had so completely split the maths from the people doing the knowing that she had lost any sense of knowledge being generated and held inside relationships; here between teachers and pupils. Certainly the thrust and direction of all formal educative 
processes would support her in developing such a split. A suggestion that might flow from the pupils' focus seems to be that, for these pupils at least, what the subject is, epistemologically speaking, is as much about the teacher and the room it is experienced in as it is about the content or other more 'adult' or teacherly concerns. In this context, maths is as much about 'after lunch on Tuesday', 'Room 131' and 'Ms Prittstick' as it is about 'algebra', 'shape' or 'long division'. It also suggests a different way of thinking about the problems or difficulties of knowledge transfer although it is not my intention to explore that here.

So, the children were determined to stay with their subjective experiences ("Is that different to other subjects?" / "I think it is different teachers.") and were very focused on getting the interviewer to understand their standpoint. In all the interviews, the pupils spoke to her as a colleague, while she listened as a teacher. And yet the pupils were remarkably persistent in their efforts to get her to hear what they wanted to tell her: about their learning and their relationship with their teacher who was part of that learning and knowing. In an exchange with another group of pupils the teacher/interviewer kept moving the topic away from the intersubjectivity the pupils were focussed on, eventually changing the topic in an apparent attempt to get them to talk about mathematics rather than their maths teacher. However, in response to her new question about activities they persisted in describing Steven's way of working:

Int What activities do you not like?

What's the best? He explains more than other teachers. If you don't understand it and he tries to give you more details.

He doesn't lose his temper he just deals with them [people who mess about], he just sends them out straight away.

Instead of dealing with it in the class and shouting and disrupting the lesson he speaks to them outside and then brings them in.

So, the teacher/interviewer was not managing to 'hear' what she was being told and, as the interviews progressed the pupils gradually gave up and resorted to ever shorter responses.

\section{The Pupils' agenda: mutuality, respect and the 'expert' teacher}

When asked about how they learn in maths lessons about half the comments 
mentioned things like equipment, working in books, working things out, and memorising. However, other comments were rather different

Sometimes when the class is quiet you can concentrate more and somehow the class is always quiet in maths.

It is good working in partners because the people that aren't that good at maths you can help them and they can help you.

Sometimes [doing group activities is] not good because people in your group ... let you down.

We cooperate with each other and the teacher.

There is something here about mutuality, about the pupils' awareness of the 'groupness' of the group or class, particularly the larger notion of the group as 'classwith- teacher' and the way they are inextricably bound together. At least some of the pupils appear to have had a more collegiate notion of the classroom than the more usual 'us and them' of the 'class and a teacher' that most adults work with. This group orientation was also something that was notable in the primary school project. It stands in stark contrast to teacher/adult privileging the autonomous individual. This other awareness is what draws me to group psychoanalytic theories (see also Bibby 2008).

The next, rather long extract, starts with a group of secondary pupils who are contrasting their experiences with Steven and a student teacher. The notion of mutuality is extended in this exchange. As it is not always clear where comparisons are being drawn, I underline the comments that refer to Steven

Int What is the best way of learning in maths lessons?

Doing it off the board and the teacher helps you out because when you do it from the books she just speaks and gets annoyed If you get to speak in front of the whole class explaining why you think it's this and like everyone sharing their own methods, instead of the teacher we've got right now is a trainee and she says we can only use this method. She only gives us two methods and we have to use them, Otherwise we can all share out own methods and I think it would be more easier. 
Sometimes we ask her like for help and she doesn't understand it. She tells us what she thinks I said and then walks away and helps like five other people before she comes back.

We need some expert teacher, that's what we need.

Int So you learn best when you feel you're being taught by someone who's got very good knowledge? [...]

Yeah, with Steven everyone learns a lot

Yeah, it's a bit funny. Sometimes we're naughty... but I think we learn better when we know someone's actually an expert and will actually listen to you.

He can handle the class well

If people play up he will deal with them

In the first set of responses, where contrasts are being drawn, the pupils make a distinction between a teacher who doesn't know how to listen and one who does; between a (student) teacher who feels a need to exert a tight and highly restrictive form of control; and a teacher who can provide the psychic and emotional space for them to explore explanations, but who, none-the-less, has complete control. That the pupils chose to draw attention to this quality in the second set of responses suggests that not only were they aware of their behaviour being their choice, but that control of a particular kind is an important prerequisite for enabling them to learn.

An important theme across the first two sets of responses is the different definitions of 'expert' that are being drawn upon. The teacher/interviewer interprets 'expert' to mean someone who's got very good knowledge; a familiar meaning to teachers and researchers (Shulman 1987; Ma 1999). However, the pupils appear to have a different meaning. When they talk of Steven being an 'expert teacher' they seem to be saying that he is 'emotionally expert' or perhaps 'socially expert'; that is that he can handle them, and his relationships with them, confidently. We can hear them valuing being able to trust him to treat them and their learning seriously and with respect, that it is important that their teacher shows caring, looks after their feelings and is empathic. Such expertise, as I suggested earlier, does not necessarily develop with experience 
and it is not a skill amenable to being taught. These themes return differently in relation to the interviews with the primary school pupils.

The secondary pupils also clearly and positively valued what we might think of as Steven's generosity in relation to them

Int Is [how you learn] different from other subjects? Do you learn in other ways?

Yes. He sometimes gives us little riddles on how to remember about kilograms and stuff so it is kind of different because he helps us learn rhymes and stuff. He gives us little hints.

He gives you like activities to do instead of just going straight on working in books or something he gives you more activities to do and if you're in science and stuff they just make you look in the board and do other things in books and stuff.

Here the pupils seem to be indicating that their teacher 'gives them stuff', that there is interaction, a movement from the teacher towards them as people, and they feel thought about, 'seen'. They seem to be valuing this and expressing gratitude and pleasure at what they experienced as his generosity in providing social and emotional space, a generosity of spirit perhaps.

Reading this with Bion it appears that we can develop a sense of what $\mathrm{K}$ links might look like in a classroom, of what relationships that can tolerate not knowing look like, of how teachers and pupils might work together to hold the anxiety and difficulty of coming to know (about each other and the associated passions and content knowledges) in mutual relationships, of the emotional flows associated with an ability to tolerate thoughts, think and to learn. We can begin to see the complexity of the $\mathrm{K}$ link

$\mathrm{K}$ [stands in] for both the problem of realizing 'knowledge' and for accepting new ideas and new people as valuable and worthy. 'Minus $\mathrm{K}$ ' is a destructive attack upon the links between ideas and people. (Britzman 2003, 25)

Moving to the primary school data provides us with contrast that demonstrates the difficulties associated with $-\mathrm{K}$ links, that is, with refused or blocked relationships. This data came from pupils in Rachel's class. She was a less experienced and less 
confident teacher who gave a strong 'performance' of teaching in the terms expressed in national policy (e.g. Department for Education and Skills 2003; Department for Education and Employment 1998, 1999). Her work was objectives-driven, often scripted by downloaded lesson plans, and delivered with 'pace' interpreted as a kind of brisk, snappy speed. It is important to remember that Rachel taught under conditions characterised by a high level of surveillance within the school and pressure to attain targets whose achievement was examined three times per year by the head teacher.

\section{Data from Primary school pupils}

The first set of data extracts come from an interview conducted towards the end of the Autumn term with three girls from Rachel's class (Sophie, Sally and Sabrina). They had been telling the researcher about drawings they had done showing a time when they were learning and a time when they didn't learn (Mauthner 1997). They had been encouraged to use bubbles to indicate what the different people depicted were saying or thinking. This extract comes from early in the interview and follows a section where they have talked about various teachers (as people) and their teaching (what it was like to be in their classes). Here, in contrast to the secondary school pupils' feelings about their teacher, we get some insight into children's contained hurt and anger

Sophie OK, Rachel, she sometimes ignores me and stuff and I don't really like it $[\ldots .$.$] It hurts my feelings$

Int. It hurts your feelings, yeah, and I wonder does that make it easier to learn or harder?

So. Harder, and like I open my book and I see that I get all the questions wrong, wrong, wrong, wrong

Int. Oh no, so you feel ignored and then you're feeling that you haven't got it right? [...]

So. $\quad . .$. and it's not my fault that I got everything wrong, it's Rachel's fault that I got everything wrong

Int. So what happens when you get it wrong 
So. I feel guilty [Because?] Rachel ignored me [...] I don't know why I feel guilty.....it's still quite my fault because I got the questions wrong a bit, but it's normally her fault

In this extract we can hear Sophie feeling unseen (she sometimes ignores me), judged (I get all the questions wrong, wrong, wrong), persecuted (its her fault), and strangely guilty. Less guarded responses follow on from Sophie's comments

Sally when you keep on being left out, you think of something, you think that oh maybe they don't like you and that's how I feel

Int. And what happens to you when you're trying to get on with learning things and you feel that your teacher doesn't like you? Does that make a difference

Sa. Yes, it's a bit difficult to like concentrate and then she's like 'you're not concentrating properly', but then when you tell her that 'you're leaving me out' then she doesn't know how you feel because it's not happening to her!

Int. Because she's not being left out?

Sa. Yeah 'cos she's being, like everyone's surrounding her going Rachel, Rachel!

So. If I was Rachel yeah and Rachel was me yeah, I'd just squash her like a fly (Laugher from all 3)

$[\ldots]$

Sa. I would ignore them or this is what sometimes I feel like to do with this boy in my maths group, getting a ruler and whacking it on his head.... yeah that's what I feel like to do with Rachel, 'cos teachers need things like that ...

Here we get a sense of Rachel blocking the relationships; of the extent to which feeling left out could leave these girls feeling anxious and rejected. They express a sense of injustice that the teacher has no sense of how they feel, that she lacks empathy. And their violent fantasies suggest a level of contained rage that remains quite surprising. The isolation or sense of disconnection from the teacher described by 
the girls in this rather general discussion was echoed by others who told of similar feelings if rather less graphically.

\section{Coming to terms with a blocked relationship}

The children had learned a variety of ways of coping with this sense of disconnection from their teacher. In the extracts below Shanhrul and Houssain are talking together about what life was like for them in maths lessons, they also mention Jack who they often worked with. This paired interview (with the author) was conducted towards the end of the summer term. They describe vividly the tensions between individual and collaborative working

Shanhrul (touching Houssain's arm) he works slowly but it is exciting. He needs help from Jack - they do it together

Int. is that right? (H nods) Does Jack help you or do you help Jack?

$\mathrm{H} \quad$ we help each other

S $\quad[\ldots]$ no one wants to be my partner, that's why I have to do it myself The boys explained the need to 'go fast' and to 'go past the others'. That is, they raced to the bottom of the page from the text book or the worksheet they had been set. Shanhrul and I reflected on how, early in the year when he was still a relative newcomer to the school, we used to enjoy discussing maths when I was observing in the classroom. He and I would sometimes share methods or compare ways of thinking. However, later in the year he had been drawn further into the prevailling school culture and there was no longer any time to talk in maths lessons, he studiously ignored me if I sat near him. This may have been a result of a number of factors but the pace of the lessons had undoubtedly picked up and was associated with an increasing focus on reaching performance levels. Collaboration had come to mean checking each other's answers so both could do as well as possible, any desire to strive for understanding had diminished or been lost. The pressure from outside was growing ahead of anticipated national tests. The fears displayed here are familiar from other places (For example Newstead 1998)

S you want to get all the scores right, you want to get [National Curriculum level] 5 at the end

$\mathrm{H} \quad$ yeah and you don't want to get any wrong and your heart goes beatin’

S Beating so fast 
$\mathrm{H} \quad$ Boom boom boom

Int. Your heart beats very fast

$\mathrm{H} \quad$ Yeah - am I going to get it all right?

Like children reported in other studies (see for example Reay 2002; Reay \& Wiliam 1999), the boys here struggled to make sense of what the grade labels they were acquiring meant. They put considerable mental and emotional energy into this identity work (Wexler 1988) as they struggled to maintain their sense of self and their peer relationships under these new and shifting conditions. In doing this they were given no help by the school or their teacher. Levels were aspirational and declared without mediation; their fragmentation into sublevels appeared only to add to the confusion.

Int. what does that mean? If you've got a $3 \mathrm{a}$ is that good or

$\mathrm{H}$ that's good but I have to do much better. You got to get 4

S like me and and ... you got to get $4 \mathrm{a}$ and I got $4 \mathrm{~b}$ but you got to get $4 \mathrm{a}$ and he got $3 \mathrm{a}$

Int. So is $3 a$ better than $3 b$ ?

$\mathrm{S} \quad$ Yeah $3 \mathrm{a}$ is better than $3 \mathrm{~b}[\ldots]$

Int. I don't know - what does it mean then? When you tell us. If I say to you 'Houssain is 3a' what does that make you think?

S You're meant to get $4 \mathrm{a}$ and if you don't go fast - 3a - that means you're not that good but you are good. And if you don't go past 2a you're very, very ... you're bad ((spits this last word out)) excellently bad!

Int. Does it make you a bad person?

S No, you don't work properly, you don't work hard

Int. So does Houssain not work properly?

S No, he does - he is good - if you don't work properly you are bad and get a $2 \mathrm{a}$ in your test

After a year of learning maths with Rachel, Shanhrul and Houssain had given up on the painful process of trying to form an emotional connection with her. They had consistently experienced Rachel as emotionally absent and withholding in the 
classroom (she rarely chose to talk directly to individuals preferring to mark books or to 'patrol' the classroom while children worked). The suggestion here is that she (unconsciously) blocked the relationship and refused to allow a $\mathrm{K}$ link to develop. As a result any topics or skills she tried to teach were inaccessible; the children's route to thinking about and understanding these necessarily went (or failed to go) through her. The girls' talk provided graphic evidence of why they might seek to protect themselves from some of the affects of the particular pedagogic relationship they were experiencing. Similarly, in contrasting their relationship to their loved teacher, Steven, with their relationship with the student teacher, we can see how, in some circumstances, emotional engagement with a teacher might feel risky or impossible and so also be resisted by the learners.

The long-term impact of these struggles to understand experiences in the midst of tensions is difficult to gauge. As Grumet has argued, 'the autobiographical story lies somewhere between personal myths, which come from without, and personal fictions which come from within' (in Pitt, Robertson \& Todd 1998, 3) - this reinforces the centrality to identity work of the relationship that embraces such a struggle. In a relationship that doesn't see or acknowledge one's struggles, unrecognisable personal myths might develop warping the identity work/autobiographical story.

These primary school data provide a glimpse of what can happen when the facilitating aspects of pedagogic relationships are experienced as missing; of the anger, hurt and guilt associated with feeling judged, left out and persecuted, of the way the pupils could be left feeling 'unseen' by a teacher who apparently failed to display any empathy or thoughtfulness towards them. Is it still reasonable for Shanhrul and Houssain to be friends? Are they still the same in some sense, even if they are labelled differently? We can begin to get a sense of the way in which the content of the lessons loses its meaning in a blocked pedagogic relationship. The pupils were forced to turn back to each other to try to develop meaning - and they lacked the tools for doing so. How can we make sense of this data and of the emergent learner-sense of 'pedagogy'? It certainly raises important challenges to our adult/teacher uses of the term.

\section{A learner-centred pedagogy}

A difficulty with developing a learner-centred notion of pedagogy is the nebulous 
nature of the demands. From the analysis above an inchoate definition would stress the importance of a caring teacher who is able to 'see', 'hear' and 'value' each pupil and who respects them individually and collectively; someone who not only knows their subject but is also 'socially' expert and can manage relationships reasonably well; someone empathic who can be generous with their time and energies. It is easy to dismiss such desires as a list of intangible qualities that are too personal to be reasonable, more aesthetic than practical.

In drawing on the work of Bion I have begun the work of discursively mapping these nebulous, desired qualities onto a set of metaphors that might enable us to think about the pedagogies implied somewhat differently. In using the small portion of Bion's theories presented here we begin to get a sense of what is at stake in pedagogic relationships: the ways in which these structure and enable different kinds of learning and knowledge creation, some more academically generative than others. The difficult work of finding ways of thinking and talking non-judgementally about the unconscious aspects of pedagogic relationships has a long history but does not sit well in the current English policy context. To address the concerns of teachers and parents, such as those reported by the English Primary Review, psychoanalytically informed work undertaken in different historical contexts needs reconsidering. Or rather, psychoanalytic theories need to be brought again to bear on newly expressed educational anxieties, desires, fantasies and defences and the way these play out in current pedagogic relationships. In the discussion I consider why enacting a learnercentred pedagogy might feel so difficult.

\section{Discussion}

My experiences and the extended data I have presented demonstrate the ways in which knowing and learning are bound up in the unconscious emotional flows of relationships. The data have provided some examples of how mental growth might develop or be blocked by the relationships within the classroom. Because of the power differentials between the teacher and the pupils, and the reliance of the pupils on the teachers for much of the ethos of the classroom, the teacher maintains a pivotal role in setting up the conditions under which particular kinds of relationship are more or less likely to form. In this paper I have chosen to draw on Bion's notion of a K link which is 'that linkage present when one is in the process of getting to know the other 
in an emotional sense, and this is to be clearly distinguished from the sort of knowing that means having a piece of knowledge about someone or something.' (Symington $\&$ Symington 1996, 28)

In the data it is notable that the children linked their learning to the teacher who they did the learning with, in other words, they conceived of themselves and their learning in the relationships. As indicated above, Bion suggests that learning and thinking can only take place when the links between ideas and people can be tolerated. This is borne out in the data where 'knowledge about' - curriculum content knowledge - was only acceptable when it was offered intimately bound to the $\mathrm{K}$ relationships in the classroom; the emotional connections to, and work with, teachers and peers. When curriculum content knowledge was presented alongside a denial of that interconnectedness, (in a $-\mathrm{K}$ relationship) it was reduced to unsatisfying, disconnected knowledge. Bion provides us with tools with which to gain some purchase on the (dis)connections evident in the data.

The process of getting to know someone involves pain, frustration, loneliness and letting go of idealisations. 'Obtaining a piece of knowledge about a person [or a thing] does not involve these states, in fact it is like cannibalism, taking something and avoiding emotional involvement' (Symington \& Symington 1996, 28). In their denial of the central importance of emotional engagement, both the student teacher and Rachel offered abstracted knowledge which the children didn't so much reject, as find themselves unable to digest or process. Their focus remained on the blocked relationship inside which the thinking couldn't happen and, in the case of the primary school pupils, they expressed their anger at the person doing the blocking. The avoidance of the pain, frustration and loneliness of the $\mathrm{K}$ link resulted in the link being broken leading to a relationship characterised by a reversal, $\mathrm{a}-\mathrm{K}$ relationship, in which the link was blocked.

In a $-\mathrm{K}$ relationship the process of coming to know is stopped and may even reverse stripping previously meaningful units of their meaning. I suggest that in this way, we can understand Shanhrul and Houssain's loss of meaning in relation to maths. In the blocked relationship with their teacher, blocked because Rachel was not (at that time or in that place) able tolerate the difficult emotional demands of the classroom, they struggled to give the tasks meaning and so turned them into games: racing to the bottom of pages, stopping looking for meaning within the maths and turning instead 
to each other. There was also evidence of this in the Y8 students' talk of the way the student teacher blocked their ability to engage with the maths whereas Steven was more often able to keep the maths meaningful within an engaged relationship.

The denial of the centrality of these mutual relationships by many teachers seems ever more problematic. Again, this is not a conscious denial. Psychoanalytically, denial is a defence used to protect the psyche from unbearable knowledge. In thinking through why teachers (newly qualified or experienced) might deny the importance of the kinds of relationships they develop with their pupils one suggestion might be that, in an effort to preserve a sense of professional efficacy, teachers resist thinking about learners' responses to their actions. After all, while it can be almost enjoyable to discover and discuss the failings of others, facing the responsibilities we have for the affects of our own actions is far more problematic. Another reason for denying the importance of relationships might be that, in response to cultural and policy idealisations of knowledge, learning and the role of the teacher, some teachers might develop a terror of what it would mean not to accept these formulations, to accept teaching as, in Freud's terms, an impossible profession 'in which one can be sure before hand of achieving unsatisfying results' (1937, 248). (See Britzman 2003 for a discussion of idealisation in education, and Bibby 2009).

Perhaps too, it is not surprising that teachers withdraw from the difficulties presented by doing emotional work with so many people every day. I wish to emphasise that it is neither possible nor desirable to enact policies that prescribe a different way of being. At any moment we may or may not be not able to engage fully in contexts which we find challenging but I suggest that to increase our chances of managing it we need tools and metaphors with which to rethink those challenging classroom environments. My suggestion is that refocusing on unconscious processes enacted in the classroom offers a way beyond the stuckness of accepting or rejecting prescriptive 'advice' on how to teach better or how to deal with 'maladaptive' pupils. It is not new to suggest that we need to look beyond the actions of individuals (Parsons 2005), the choice of where to look, or rather, where to listen, may be less usual. Focussing on content and denying the relatedness of the classroom can provide a welcome distraction from, and excuse not to undertake the difficult emotional work required to sustain a relationship. This is not to say that the content isn't important, I am not advocating that we empty teaching of its purposes, but it is to suggest that the 
pedagogic end or purpose of the teaching task needs attention that is as close and sustained as the attention paid to the content. Further, I suggest that children's pedagogic requirements need to be part of what informs the professional thinking of teachers.

But how can the teachers learn and develop their teaching if they are not prepared to acknowledge their end of the $\mathrm{K}$ link? If they are not prepared to enter into the difficulty of the being in and with in the classroom? What happens to relationships when one end of them is attacking the link? What do we learn in those contexts? Is the attack on the link experienced as an attack on me? This is certainly what some of the children's data suggests. Key to the discussion here is a need to acknowledge that the principle that we can tolerate pain and uncertainty would apply as much to teachers in the classroom as to their pupils. So where a teacher 'chooses' to evade the pain and difficulty of emotional engagement with pupils, they block mental growth and learning in themselves as well as in their pupils making reflection and professional development problematic. For both teachers and pupils, repairing a relationship you have colluded in killing may also be too much of a mountain to climb. Perhaps there is also shame at the way you've got to where you've ended up? Again, I stress this is not about 'good' and 'bad' teachers. Nor am I suggesting that teachers need therapy (although they might find supervision helpful) or that teaching needs to take a 'therapeutic' turn. What I am suggesting is that there is a need for a language that makes the nature and qualities of relationships visible and enables them to become objects for (non-judgemental) consideration. Thinking this through in ways that might enable teachers to move past the terrors of performativity (Ball 2003) engendered in their relationships with their employers, requires more thought.

... discussions of knowledge actually signal a loss of faith when they are arranged tightly in the actions of taxonomies, behavioural objectives, measurable outcomes, and institutional goals. In this design [...] knowledge only knowledge of actions. The difficult work of thinkers meeting their thoughts - through symbolization, interpretation, and persuasion - is foreclosed. (Britzman 2003, 124)

It is interesting that, in England in recent years, the major reforms represented by the National Literacy and Numeracy Strategies (DfEE 1998; 1999) have, it is claimed, failed to have any lasting impact on the patterns of classroom interaction although 
they may have impacted content and organisational features (Alexander 2005). That the pattern of interactions remains unchanged suggests that the nature of the relationships is static with some teachers managing to generate and work with $\mathrm{K}$ links and others working counter-productively with $-\mathrm{K}$ links. It seems that there may be something embedded in individual, professional and institutional psyches - at local and national levels that is working hard to maintain the status quo and to avoid the difficulty of these 'higher' level relationships - that there exist blocked relationships higher up the learning food-chain.

\section{References}

Alexander, R. (2005). Towards dialogic teaching: rethinking classroom talk. 2nd ed. Cambridge: Dialogos.

Ball, S. J. (2003). The teacher's soul and the terrors of performativity. Journal of Education Policy, 18 (2), 215-228.

Benjamin, J. (2004). Beyond doer and done to: an intersubjective view of thirdness. Psychoanalytic Quarterly, LXXIII, 5-46.

Bibby, T. (2002). Shame: an emotional response to doing mathematics as an adult and a teacher. British Educational Research Journal, 28(5), 705-722.

- (2008). The experience of learning in classrooms: moving beyond Vygotsky. In T. Brown (Ed.), The psychology of mathematics education: A psychoanalytic displacement. Rotterdam: Sense.

. (2009) How do pedagogic practices impact on learner identities in mathematics? A psychoanalytically framed response. In Mathematical relationships in education, eds. L. Black, H. Mendick, \& Y. Solomon. London: Routledge.

Bion, W. R. (1961). Experiences in groups and other papers. 2004 ed. Hove, East Sussex: Brunner-Routledge. . (1962). Learning from experience. 1989 ed. London: Karnac Books. 
Britzman, D. (2003). After-Education: Anna Freud, Melanie Klein, and psychoanalytic histories of learning. Albany: State University of New York Press.

Curtis, P. (2008). Under-funded primary schools fail to teach basic literacy, says key review. The Guardian. Friday February 29th.

Department for Education \& Employment. (1998). National Numeracy Strategy: A framework for mathematics (November, 1998 ed.). London: HMSO.

_. (1999). The National Numeracy Strategy: Framework for teaching mathematics from Reception to Year 6. London: DfEE.

Department for Education \& Skills. (2003). Excellence and enjoyment: a strategy for Primary schools. London: DfES.

Felman, S. (1987) Jacques Lacan and the adventure of insight: psychoanalysis in contemporary culture. Cambridge, MA: Harvard University Press.

Freud, S. (1937) Analysis terminable and interminable. In J. Strachey \& A. Freud Eds. The standard edition of the complete psychological works of Sigmund Freud London: Hogarth Press and Institute for Psychoanalysis. Volume 23, 209-254.

Lucey, H., J. Melody, \& V. Walkerdine. (2003). Uneasy hybrids: psychosocial aspects of becoming educationally successful working-class young women. Gender and Education, 15 (3), 285-299.

Ma, L. (1999). Knowing and teaching mathematics: Teachers' understanding of fundamental mathematics in China and the United States. Mahwah, New Jersey: Lawrence Erlbaum.

Mauthner, M. (1997). Methodological aspects of collecting data from children: lessons from three research projects. Children \& Society, no. 11, 16-28.

Newstead, K. (1998). Aspects of children's mathematics anxiety. Educational Studies of Mathematics 36 (1), 53-71.

Palmer, S. (2006) Toxic childhood: How the modern world is damaging our children and what we can do about it. London: Orion. 
Parsons, C. (2005). School exclusion: the will to punish. British Journal of Educational Studies, 53 (2), 187-211.

Pitt, A., J. P. Robertson, \& S. Todd. (1998). Psychoanalytic encounters: Putting pedagogy on the couch. Journal of Curriculum Theorizing, 14(2), 2-7.

Reay, D. (2002). Shaun's story: troubling discourses of white working-class masculinities. Gender and Education, 14 (3), 221-234.

Reay, D., \& D. Wiliam. (1999). 'I'll be a nothing': structure, agency and the construction of identity through assessment. British Educational Research Journal, 25 (3), 343-354.

Sadler, R. (2007) Perils in the meticulous specification of goals and assessment criteria. Assessment in education: principles, policy and practice. 14 (3), 387392.

Shulman, L. S. (1987). Knowledge and teaching: foundations of the new reform. Harvard Educational Review, 57 (1), 1-22.

Smith, A. (2004) Making mathematics count. London: The Stationary Office.

Symington, J., \& N. Symington. (1996). The clinical thinking of Wilfred Bion. 2004 ed. London: Routledge.

Torrance, H. (2007) Assessment as learning? How the use of explicit learning objectives, assessment criteria and feedback in post-secondary education and training can come to dominate learning. Assessment in education: principles, policy and practice. 14 (3), 281-294.

Watkins, C., \& P. Mortimore. (1999). Pedagogy: what do we know? In Understanding pedagogy and its impact on learning, ed P. Mortimore 1-20. London: Paul Chapman/Sage.

Webb, R. \& G. Vulliamy. (2006). The impact of New Labour's education policy on teachers and teaching at Key Stage 2. Forum. 48 (2), 145-157.

Wexler, P. (1988). Symbolic economy of identity and denial of labor. Race, class and gender in American education. L. Weis New York, SUNY Albany, 302-315. 
i i See www.primaryreview.org.uk

ii ESRC grant RES 000-22-1272 Children's learner-identities in mathematic at Key Stage 2

iii Sections of transcript are continuous unless otherwise stated. Responses on a new line are from a new speaker 